\title{
Estudio y caracterización del Autoinyectable de atropina- oxima DEF. Diseño de nuevos Autoinyectables para Defensa NBQ y otros medicamentos de urgencia
}

\author{
Sánchez Ramos JJ. ${ }^{1}$
}

Sanid. mil. 2014; 70 (1): 7-19; ISSN: 1887-8571

\begin{abstract}
RESUMEN
Antecedentes: Los autoinyectables (AI) son dispositivos para administración de medicamentos de urgencia por vía parenteral (i.m.) por el afectado o un compañero. Tienen interés militar en Defensa NBQ para la administración de antídotos contra agentes nerviosos y otros medicamentos de urgencia. Se estiman necesarios cinco nuevos AI que pueden ser fabricados por los Servicios Farmacéuticos de la Defensa, además del que se fabrica en la actualidad. Objetivos: Presentación del Autoinyectable AJP (AI-AJP) y su preparado Autoinyectable de atropina-oxima DEF (AI-AOD), resultantes de la I+D sobre AI en el CEMILFARDEF, y su caracterización. Aplicación de resultados al diseño de cinco nuevos AI de interés en Defensa NBQ. Métodos: Ante la falta de ensayos y criterios de valoración oficiales para AI, se realiza una revisión bibliográfica y un estudio retrospectivo sobre la investigación básica llevada a cabo durante dos décadas en el desarrollo y fabricación del AI-AJP, estableciendo procedimientos de caracterización y evaluación de la calidad farmacéutica y propiedades funcionales en condiciones normales y de estrés. Mediante programas ACAD y ensayos galénicos se diseñan cinco nuevos AI. Resultados: Obtención del AI-AJP y su presentación AI-AOD. Presentación de sus componentes, funcionamiento y resultados del análisis de las variables implicadas en su diseño, producción y control: usabilidad, portabilidad, funcionamiento, fuerzas, inyectabilidad, contenidos, esterilidad, partículas, pirógenos, estabilidad, y resistencia. Se expone el diseño de cinco nuevos AI, a los que son aplicables los resultados obtenidos en este estudio. Conclusión: El Autoinyectable AJP cumple los requisitos exigidos por el estado actual de la ciencia, es seguro en funcionamiento, y robusto en resistencia al estrés estático y dinámico. Es estable y la inyección consistente. Se han diseñado cinco nuevos AI (Atropina, Diazepam, Multicomponentes, Morfina y Epinefrina) necesarios en Defensa NBQ y situaciones de urgencia.
\end{abstract}

PALABRAS CLAVE: Autoinyectables, Antídotos NBQ, Medicamentos de urgencia.

Study and characterization of the atropine-oxime autoinjector DEF. Design of new autoinjectors for NBC Defense and other emergency drugs SUMMARY: Background: Autoinjectors (AI) are devices for parenteral administration (im) of emergency medications for self or buddy aid. They have NBC Defence military interest for the administration of antidotes against nerve agents and other emergency medications. It is needed five new AI that can be manufactured by the Spanish Pharmaceutical Services, in addition to the one currently made. Objectives: AJP Autoinjector (AI-AJP) presentation and its military medication Autoinjector of atropine-oxime DEF (AI-AOD), as an I+D process result about AI carry out by the Military Pharmaceutical Services, and its characterization. The results are applied to the design of five new AI for NBC Defense. Methods: In the absence of formal testing and evaluation criteria for these devices, the scientific publications and the experience gained from two decades of development and manufacture of AI-AJP have been reviewed, to set characterization procedures, and to evaluate the pharmaceutical quality and the functional properties under normal conditions and in static and dynamic stress. By mean of ACAD and pharmaceutical development programs, five new AI have been designed. Results: AI-AJP availability, and its presentation AI-AOD. Components, operation, and results presentation from the analysis of design, process and control variables: usability, portability, dynamic operation, involved forces, injectability, contents, sterility, particles, pyrogens, stability, and physical resistance. The new five AI designs and characteristics are exposed, to which the results obtained in this study are applicable. Conclusion: The AJP Autoinyector meets the requirements demanded by the current science state, is safe in operation, and robust under static and dynamic stress. It is stable and the injection is consistent. Five new AI have been designed (Atropine, Diazepam, Multi-components, Morphine, and Epinephrine) needed to NBC Defense and Emergencies.

KEY WORDS: Autoinjectors, NBC antidotes, First-line medicines.

\section{INTRODUCCIÓN}

Los autoinyectables (AI) constituyen una forma de presentación de medicamentos en dosis unitaria inyectable para el tra-

${ }^{1}$ Tcol. Farmacéutico.

Centro Militar de Farmacia de la Defensa. Córdoba. España.

Dirección para correspondencia: Centro Militar de Farmacia de la Defensa (Córdoba). Avenida de Rabanales, 1.14010-Córdoba.jsanram@oc.mde.es

Recibido: 28 de junio de 2013

Aceptado: 9 de diciembre de 2013 tamiento propio o de un compañero en casos de urgencia vital. Liberan de forma automática una dosis exacta, estéril, apirógena y libre de partículas, de un medicamento inyectable. Se presentan perfectamente identificados y listos para ser administrados sin necesidad de trasvases, de forma rápida, segura y eficaz, con solo activar su mecanismo de disparo. Están indicados en procesos extrahospitalarios muy rápidos en su comienzo y evolución a gravedad, en los que la administración intramuscular de un medicamento de primera línea puede salvar la vida del afectado, en tanto es evacuado y recibe atención sanitaria especializada. La anafilaxia grave, especialmente la producida por picadura de 


\section{JJ. Sánchez Ramos}

insectos ${ }^{1}$, o la intoxicación con agentes nerviosos como tabún (GA), sarín (GB), soman (GD), o VX, que pueden ser usados como armas en ataques químicos sobre la población civil o mi$\operatorname{litar}^{2}$, producen estas situaciones extrahospitalarias de urgencia vital. En circunstancias de aislamiento, esta acción terapéutica solo puede ser llevada a cabo mediante un AI de epinefrina en la anafilaxia grave ${ }^{1}$, o mediante AI para Defensa NBQ en el caso de los agentes nerviosos de guerra química. En una agresión de combate, la terapia inmediata post-exposición consiste en la administración intramuscular mediante AI, de atropina, oximas (pralidoxima, obidoxima o HI6) y diazepam, solos o en combinación. Si posteriormente la baja permanece sintomática, serán necesarios AI adicionales de oxima y atropina, pauta que depende de la doctrina sanitaria de cada nación ${ }^{3}$.

Lo impredecible de la exposición al agente desencadenante, y la rigurosidad del proceso clínico resultante hace necesario, en primer lugar, que cada individuo del grupo de riesgo lleve siempre consigo al menos un AI (portabilidad); en segundo lugar, que sea capaz de utilizarlo correctamente, en el momento oportuno, y en las condiciones de estrés que acompañan al ataque (user-friendly); y en tercer lugar, que el AI sea seguro en su funcionamiento. El fallo o el retraso en la administración pueden tener consecuencias fatales; la administración correcta y oportuna mejora el pronóstico y los resultados finales ${ }^{4}$. Los antídotos alcanzan la circulación general en la mitad de tiempo que con la administración tradicional mediante jeringa/aguja ${ }^{2,5}$.

Fue durante la Segunda Guerra Mundial cuando se hizo evidente la necesidad de un dispositivo para la rápida administración parenteral de medicamentos de urgencia por el propio combatiente. El Syrette, introducido en el ejército norteamericano en $1950^{6}$, fue uno de los primeros AI, formado por un tubo de metal flexible similar a un tubo de pomada oftálmica, con una aguja y su protector acoplados; desarrollado para inyección de morfina como analgésico potente, presentó problemas de esterilidad, estabilidad y fugas. Desde entonces, la tecnología farmacéutica de los AI ha evolucionado hasta nuestros días como resultado de sus muchas ventajas y por el creciente interés en la medicación parenteral en unidosis ${ }^{7}$. En el ámbito militar, estos sistemas de liberación de medicamentos han experimentado un mayor desarrollo, en un intento por garantizar la administración de antídotos que protejan al combatiente en situaciones límite de estrés de campaña ${ }^{8}$. Además, el poder disuasivo de una buena contramedida sanitaria no debe ser infravalorado9. Varios AI de interés militar están disponibles en el mercado farmacéutico internacional con diferentes combinaciones de antídotos contra agentes nerviosos (atropina, obidoxima, pralidoxima y HI6) y terapias de apoyo NBQ (diazepam o avizafona como anticonvulsivante contra neurotóxicos, o morfina en casos de dolor extremo y aislamiento del afectado) $)^{10,11}$. Por otro lado, la epinefrina autoinyectable ha alcanzado una gran relevancia en el tratamiento extra-hospitalario de la anafilaxia grave ${ }^{8}$, y ha aumentado el interés civil por los dispositivos de autoinyección. Varios AI de epinefrina están actualmente autorizados para su uso en Europa ${ }^{4}$.

En esta situación del mercado mantenida durante las últimas décadas, el Autoinyectable AJP -Autoinyector de Jeringas Prellenadas- (AI-AJP) objeto de este trabajo tiene su origen a principio de los noventa, al verse reducida la disponibilidad de AI de interés militar a nivel europeo, como consecuencia de las fuertes oleadas en la demanda motivadas por conflictos internacionales globalizados con amenaza de agresión mediante armas químicas. Los AI para Defensa NBQ son medicamentos huérfanos, pues estas intoxicaciones son raras, y su interés para la industria farmacéutica civil es limitado. La Guerra del Golfo Pérsico y la Operación Tormenta del Desierto en 1991, y posteriormente el recrudecimiento del conflicto bélico con Irak en 1.998, pusieron en evidencia la insuficiente capacidad de respuesta a la demanda, que sufrieron varios países de nuestro entorno. El desabastecimiento puso de manifiesto la necesidad y las ventajas de la fabricación propia en los ejércitos de este recurso estratégico de interés militar, y aceleró el diseño y desarrollo del AI-AJP, iniciado en 1.990. Los primeros autoinyectables producidos en 1992 estaban equipados con una jeringa de vidrio con aguja insertada del sistema $S C F H_{y p a k^{R}}$ de Becton\&Dickinson, cargada con $2 \mathrm{mg}$ de sulfato de atropina y 220 $\mathrm{mg}$ de clorhidrato de obidoxima, en $1 \mathrm{ml}$. El reducido volumen, la insuficiente longitud de aguja efectiva $(<17 \mathrm{~mm})$, entre otras limitaciones, llevaron al desarrollo de una segunda generación de AI, cuya producción comenzó en 1998, equipados con una jeringa específicamente desarrollada para este AI, cargada con $2 \mathrm{mg}$ de sulfato de atropina y $600 \mathrm{mg}$ de cloruro de pralidoxima, en $3 \mathrm{ml}$. En 2006 comienza la producción de la tercera generación de AI actualmente en vigor, en la que se reduce peso y dimensiones, y se mejora su calidad y seguridad. Desde el inicio de producción en 1992 han sido fabricadas más de 300.000 unidades del Autoinyectable de atropina - oxima DEF (AI-AOD), en sus tres modalidades, por los Servicios Farmacéuticos de la Defensa.

Como objetivos, se presenta por primera vez desde su invención el Autoinyectable AJP, resultado del largo proceso de I+D que sobre autoinyectables se lleva a cabo en el Centro Militar de Farmacia de la Defensa, y que se resume en este trabajo. Se presentan y caracterizan sus componentes, dinámica de funcionamiento, y requisitos de calidad farmacéutica y funcional exigidos por el estado actual de la ciencia. Mediante un proceso cíclico experimental de diseño-producción-ensayo de prototipos, los resultados obtenidos son aplicados hasta obtener el prototipo definitivo. Mediante programas de ACAD (Application for ComputerAided Design) se generan especificaciones con las que se fabrican en taller mecánico los componentes de cada prototipo, para su caracterización tanto individual como en el conjunto del AI, y tanto en reposo como durante la activación y descarga del dispositivo. La caracterización y control de las fuentes de variabilidad, esencial para un diseño robusto de estos dispositivos ${ }^{12}$ constituye otro objetivo, y se ha llevado a cabo mediante ensayos físicos, químicos y microbiológicos. Se han evaluado y seleccionado los materiales de partida para cada componente hasta conseguir la robustez adecuada para condiciones de empleo extremas. Se han reducido en lo posible sus dimensionas y peso para facilitar su portabilidad, y se han controlado las características y exigencias particulares de cada etapa de su activación y descarga. Se ha estudiado y cualificado la integridad, esterilidad, inyectabilidad, friabilidad, estabilidad y compatibilidad ${ }^{13}$ hasta obtener resultados que garantizan su calidad, seguridad y eficacia. Finalmente, otro objetivo de este trabajo ha sido la identificación y caracterización de las variables críticas de diseño, lo que ha permitido el desarrollo de nuevos AI para Defensa NBQ y otros medicamentos de urgencia, en función de las propiedades galénicas y del volumen final de la solución inyectable. Se presentan los nuevos diseños 


\section{Estudio y caracterización del Autoinyectable de atropina-oxima DEF. Diseño de nuevos ...}

para los Autoinyectables de Atropina, Diazepam, Morfina, Epinefrina y Multicomponentes (atropina-pralidoxima-diazepam).

\section{MATERIAL Y MÉTODOS}

La metodología seguida para el estudio de los atributos y variables críticas para un AI ha sido obtenida de las publicaciones más recientes. No obstante, una necesidad compartida por los colectivos implicados en la fabricación y uso de los AI, es la falta de ensayos y criterios de valoración universalmente aceptados, estandarizados y validados, y su publicación oficial en farmacopea para estos dispositivos de urgencia vital ${ }^{4}$.

\section{Autoinyector AJP (Figuras 1, 2 y 3)}

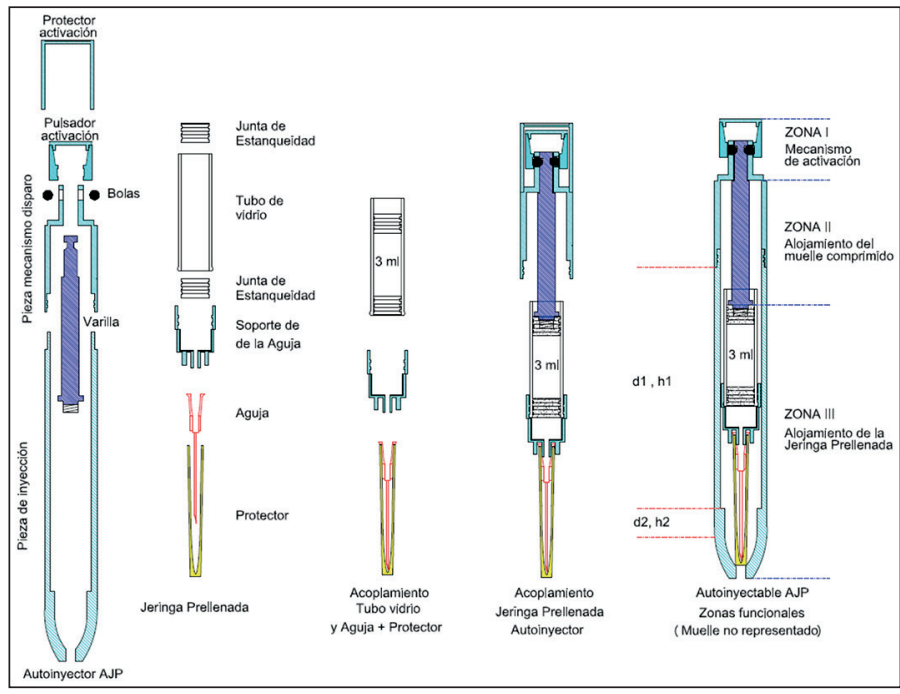

Figura 1. Autoinyector AJP, Jeringa Prellenada y Autoinyectable AJP.

\section{Producción: breve descripción}

Los componentes de plástico se fabrican, bajo especificaciones técnicas, mediante torneado (prototipos) o inyección en moldes de alta presión (producción industrial). La varilla guía del muelle es torneada en duraluminio por la alta resistencia a la tracción requerida. El muelle es fabricado por empresas especializadas. Los fabricantes de envases farmacéuticos suministran los materiales de partida para la fabricación de las jeringas. La solución inyectable se prepara y procesa en una planta de producción del CEMILFARDEF, bajo requerimientos establecidos en las actuales N.C.F. de Medicamentos ${ }^{14}$ y en las condiciones de calidad y seguridad exigidas para la fabricación de un medicamento por «vía aséptica sin esterilización terminal». Tras la colocación de la primera junta al tubo de vidrio, una llenadora automática dosifica la solución. La inserción de la segunda junta se realiza mediante vacio en una taponadora automática. La colocación del soporte de la aguja y la aguja con su protector son también procesos asépticos. Las unidades producidas son inspeccionadas para verificar la ausencia de partículas, defectos en el vidrio, y la correcta colocación de las juntas. En su conjunto, el proceso de fabricación afronta los mayores desafíos en cuanto a su esterilidad final, partículas, pirógenos, potencia, identidad, seguridad y estabilidad ${ }^{15}$.

\section{Caracterización de fuerzas}

En el funcionamiento de un AI es crítico el control de las fuerzas implicadas en su activación, descarga e inyectabilidad. Se ha utilizado un dinamómetro digital marca Mecmesin, modelo BGG-HS 200, con una célula de carga de $200 \mathrm{~N}$ y software de registro Mecmesin DataPlot. El desarrollo de fuerzas de muelles helicoidales a compresión para el AI se ha estudiado mediante un procedimiento estándar ${ }^{16}$ adaptado y validado, en el que el muelle está registrado y conducido en una sola dirección mediante su alojamiento en el interior de dos pasadores concéntricos. En la posición inicial, en la que el muelle está en reposo y libre de fuerzas, se hace el cero en el dinamómetro, y se establece la longitud $(\Delta \mathrm{L})$ que se ha de comprimir hasta la posición final en la varilla del AI. Se determinan las fuerzas en los cuartiles de compresión $(25,50$, 75 y $100 \%$ ). Se traza un mapa del perfil a compresión del muelle.

\section{Jeringa prellenada del Autoinyectable AJP (Figuras 1, 2 y 3)}

Se ha controlado la calidad de los materiales empleados en el tubo, juntas, protector, aguja y lubricante para el siliconado, especialmente en cuanto a extractables y cesiones ${ }^{17}$. La fuerza para liberar la solución contenida en la jeringa es suma de la break-loose force (fuerza máxima inicial requerida para poner en movimiento las dos juntas) y la extrusion force necesaria para mantener un flujo de solución a través de la aguja, superando la presión hidrodinámica y las fuerzas de fricción. Entre los factores que contribuyen a estas fuerzas se encuentran el siliconado del tubo (fuerzas de fricción), la geometría del tubo y la aguja (caída en la presión hidrodinámica), los atributos de la solución, la fuerza conductoras (muelle), el volumen y tiempo de inyección, y la resistencia del tejido ${ }^{12}$.

\section{Defectos físicos en el vidrio}

El cuerpo de vidrio de la jeringa forma parte del envase primario de la solución inyectable, con la que entra en contacto directo. Está fabricado en vidrio neutro de la mayor resistencia hidrolítica (Farmacopea, Tipo I) ${ }^{18}$. Por su inercia química y propiedades físicas, es el material más adecuado para el envase primario de un medicamento inyectable ${ }^{19}$. No obstante, la fragilidad del vidrio hace de la jeringa el componente más crítico tras la activación, debido al impacto tras la liberación del muelle y por la alta presión a que se somete el líquido durante la descarga. La presencia de defectos físicos en el vidrio originados durante la fabricación del tubo, potencian su fragilidad intrínseca: a) microfisuras en los bordes; b) deslaminados ocasionados por un corte irregular o por un requemado insuficiente durante su fabricación; c) zonas de tensión producidas por choque térmico entre el vidrio incandescente y partes mecánicas frías de la maquinaria que intervienen en su fabricación. La detección de estos defectos 


\section{JJ. Sánchez Ramos}

se lleva a cabo mediante observación del tubo de vidrio bajo luz polarizada. Su ausencia garantiza la integridad durante la activación y descarga, así como una correcta resistencia mecánica a la fricción durante su procesado en la industria farmacéutica.

\section{Ensayo de friabilidad}

En concordancia con lo anterior y tomando como referencia el ensayo de friabilidad para comprimidos de farmacopea [2.9.7. Eur. $P h.]^{18}$, se ha validado un procedimiento que ha resultado de gran utilidad para verificar en los tubos de vidrio la correcta resistencia mecánica a la fricción, al volteo y a los golpes. El estrés mecánico durante el ensayo provoca la rotura de los tubos defectuosos, allí donde existen sobretensiones, microfisuras, o deslaminados en el vidrio. Los tubos correctamente fabricados soportan el ensayo (ausencia de roturas o defectos físicos en el vidrio). Se lleva a cabo en el friabilator sobre una muestra de diez tubos, a 25 r.p.m. durante 4 minutos.

\section{JeringabilidadIInyectabilidad}

Estos conceptos hacen referencia al comportamiento de una formulación durante su inyección. El primero se refiere a su capacidad para pasar a través de una aguja en la transferencia desde el envase primario a la jeringa, mientras que el segundo se refiere al comportamiento durante la inyección. La inyectabilidad incluye la fuerza requerida para la inyección, la regularidad del flujo, y la ausencia de obstrucción. Depende de la viscosidad y densidad de la solución, y de la geometría de la aguja (diámetro interno, longitud y forma de la apertura $)^{12,20}$. Con agujas más finas se reduce el dolor, pero la fuerza de inyección es mayor. La inyectabilidad es un parámetro clave en el desarrollo de un AI, que se caracteriza estableciendo, mediante el dinamómetro, la fuerza para iniciar y mantener el movimiento del émbolo en el tubo de la jeringa y la capacidad para liberar la cantidad especificada de medicamento. Las farmacopeas no especifican procedimientos de ensayo. La inyección con un AI ha de ser intramuscular y a través de la ropa. La selección del diámetro y longitud óptima de la aguja es crítica. Para el AI-AOD, aguja Microlance ${ }^{\mathrm{R}} 20 \mathrm{G} 11 \frac{1}{2}$, 40x0.9mm, punta biselada de triple facetado.

La inyectabilidad depende también del grado de lubricación o siliconado de la junta de estanqueidad y del tubo de vidrio de la jeringa. Del siliconado depende también la correcta colocación de las juntas durante el taponado automático de los tubos. Las juntas de estanqueidad utilizadas en los Autoinyectables AJP son cualificadas y siliconadas por el proveedor (Becton-Dickinson, sistema Hypak $\mathrm{SCF}^{21}$ ). Los tubos de vidrio son suministrados sin siliconar por fabricantes de envases de vidrio farmacéutico (ampollas y viales). Su siliconado se realiza en la línea de producción de AI de la planta farmacéutica.

\section{Siliconado del tubo de vidrio}

Se utiliza Silicona Dow Corning 365 (emulsión de dimeticona al $35 \%$ ) autorizada para su uso en envases parenterales ${ }^{22}$. En este trabajo se han ensayado varios procedimientos y diluciones para el siliconado del tubo de vidrio, mediante la determinación de las fuerzas asociadas a la inyección, tanto en el movimiento inicial de la junta como en su deslizamiento por el tubo de vidrio. Se seleccionó la dilución que presentó los valores promedios más bajos para estas fuerzas, y el procedimiento de aplicación más simple y ajustado a los requerimientos de las N.C.F. de Medicamentos, a la vez que se verificó un residuo inferior a $0,25 \mathrm{mg}$ de aceite de silicona por centímetro cuadrado de superficie interna del tubo [3.2.8. Eur. Ph. $]^{18}$. Los tubos son esterilizados a $121^{\circ} \mathrm{C}$ durante 20 minutos.

\section{Control de esterilidad}

Los componentes que entran en contacto con la solución inyectable, y el producto intermedio y terminado son estériles. Las juntas de estanqueidad, el soporte de plástico de la aguja, la aguja y su protector, se esterilizan mediante haces de electrones de alta energía por sus fabricantes, quienes certifican su esterilidad. En el CEMILFARDEF se verifica mediante inoculación directa de muestras representativas de estos componentes en los medios de cultivo [2.6.1. Eur. Ph. $]^{18}$. El montaje y llenado de la jeringa se lleva a cabo por vía aséptica sin esterilización terminal, conforme a los requerimientos de las N.C.F.1 ${ }^{14}$. El control de esterilidad del producto terminado se realiza mediante filtración por membrana de la solución descargada por los AI [2.6.1. Eur. Ph. $]^{18}$ en un equipo Millipore Steritest Compact System, kit TZHALA210.

\section{Inercia química}

Se verifica que los componentes de plástico y elastómeros que entran en contacto con la solución inyectable (juntas de estanqueidad, soporte de la aguja y protector de la aguja) no alteran la eficacia ni la estabilidad de la solución inyectable [3.2.9. Eur. Ph. $]^{18}$. Son latex free.

\section{Autoinyectable de atropina-oxima DEF (Figuras 1, 2 y 3)}

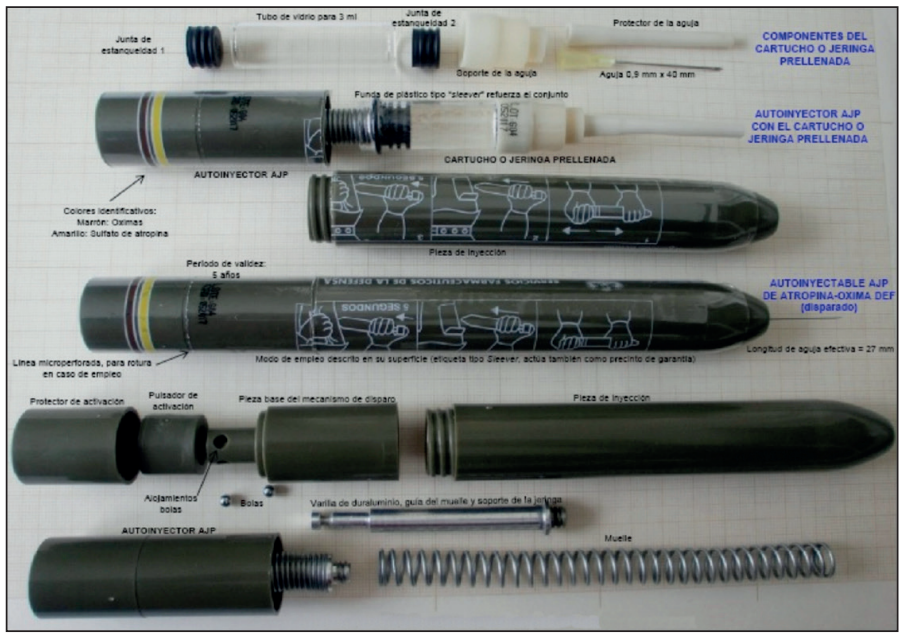

Figura 2. Autoinyectable de Atropina - Oxima DEF. Componentes. 


\section{Composición de la solución inyectable}

En la Tabla 1 se expone la composición de la solución parenteral del $A I-A O D$.

Tabla 1. Composición de la solución inyectable.

\begin{tabular}{|lcccc|}
\hline & $\begin{array}{c}\text { Por } \\
\text { litro }\end{array}$ & $\begin{array}{c}\text { Por } \\
\text { autoinyectable }\end{array}$ & $\% \mathbf{p} / \mathbf{v}$ & Autoinyección \\
\hline $\begin{array}{l}\text { Clorhidrato de } \\
\text { pralidoxima }\end{array}$ & $220 \mathrm{~g}$ & $660 \mathrm{mg}$ & 22 & $600 \mathrm{mg}$ \\
$\begin{array}{l}\text { Sulfato de atropina } \\
\text { Metabisulfito sódico }\end{array}$ & $0,733 \mathrm{~g}$ & $2,2 \mathrm{mg}$ & 0,0733 & $2 \mathrm{mg}$ \\
EDTA disódico & $0,1 \mathrm{~g}$ & $0,273 \mathrm{mg}$ & 0,01 & $0,273 \mathrm{mg}$ \\
$\begin{array}{l}\text { Agua para inyección } \\
\text { c.s.p. }\end{array}$ & 1 litro & $3 \mathrm{ml}$ & 100 & $2,727 \mathrm{ml}$ \\
\hline
\end{tabular}

$\mathrm{pH}$ entre 3.0 y 4.2; densidad de la solución inyectable $1,047 \mathrm{~g} / \mathrm{ml}$.

\section{Volúmenes de solución en el AI-AOD}

Durante su fabricación, la jeringa del AI se dosificada con $3,0 \mathrm{ml}$ de solución. Este es el volumen de diseño o volumen nominal, cuya dimensión en la jeringa determina el correcto acoplamiento de todos los componentes del AI. Debido al volumen muerto no descargado de la jeringa, el valor teórico de la autoinyección o volumen descargado es $2,727 \mathrm{ml}$ (valor calculado y verificado experimentalmente). Este volumen debe contener la dosis terapéutica de medicamentos de la autoinyección, que en el caso del $A I-A O D$ es: $600 \mathrm{mg}$ de clorhidrato de pralidoxima y $2 \mathrm{mg}$ de sulfato de atropina. La diferencia entre estos volúmenes está en el rango de tolerancia especificado en farmacopea.

\section{Análisis del contenido en principios activos}

No existe monografía específica en las farmacopeas para la solución autoinyectable de atropina y pralidoxima. Se han adaptado y validado los métodos individuales especificados en la USP2423 para determinación del contenido de cada componente en la mezcla final. El contenido en cloruro de pralidoxima se determina por HPLC y por espectrofotometría UV, sin interferencia de los restantes componentes de la solución. La determinación del contenido en sulfato de atropina requiere un proceso de extracción previo. Se ha utilizado un cromatógrafo PerkinElmer Flexar (columna Col-Analytical C18 5 um 150x4.6mm, detector Flexar UVI VIS) y un espectrofotómetro PerkinElmer Lambda 25.

\section{Contaje de partículas en la solución autoinyectable descargada}

Método de obscuración de luz mediante muestreador Hyac Royco 8000 y contador Pacific Cientific 3000. Se han determinado ocho tamaños de partícula, incluyendo los especificados en farmacopea $(10 \mu$ y $25 \mu)$ en la solución descargada tras la activación [2.9.19. Eur. $P h.]^{18}$.

\section{Pirógenos}

El ensayo de ausencia de endotoxinas bacterianas (pirógenos) en la solución descargada se llevó a cabo mediante el test enzimático LAL (Limulus Amebocyte Lysate), reactivo Pyrogent Plus Single Test Kit 24 T N-189-125 de Lonza ${ }^{R}$.

\section{Fuerza de activación}

Cada AI fue alineado vertical y horizontalmente, y fijado en el dinamómetro. La célula de carga fue posicionada por encima del pulsador y desplazada hacia abajo a una velocidad aproximada de $0,42 \mathrm{~m} / \mathrm{s}$. Se aplicó fuerza gradualmente sobre el pulsador en la dirección del eje principal del AI hasta provocar su activación. Se registra el valor máximo de fuerza alcanzado como Fuerza de Activación ${ }^{24}$.

\section{Tiempo de autoinyección}

El tiempo transcurrido desde que se presiona el pulsador de activación hasta la descarga total de la solución contenida en el AI, se registró mediante videograbación ${ }^{2}$.

\section{Longitud de aguja efectiva y dosis descargada tras la activación}

Bajo condiciones estándar de almacenamiento de los AI (temperatura $<25^{\circ} \mathrm{C}$ y ausencia de condiciones de estrés físico -caídas o sobrecarga-) se ha medido la longitud de aguja que sale del AI tras su activación, tanto en aire como a través de un doble pliegue de tejido vaquero ${ }^{25}$. Posteriormente se verificó la linealidad de la aguja y la ausencia de curvatura en su bisel. La solución descargada se recogió sobre una balanza de precisión para registrar su peso exacto. El volumen descargado se calculó a partir del peso específico de la solución inyectable de atropina-oxima $(1,047 \mathrm{~g} / \mathrm{ml})$.

\section{Ensayo de resistencia a la caída}

La robustez del $A I-A J P$ se ha estudiado simulando situaciones de la vida real en cuanto a caídas y peso a $\operatorname{soportar}^{25}$, así

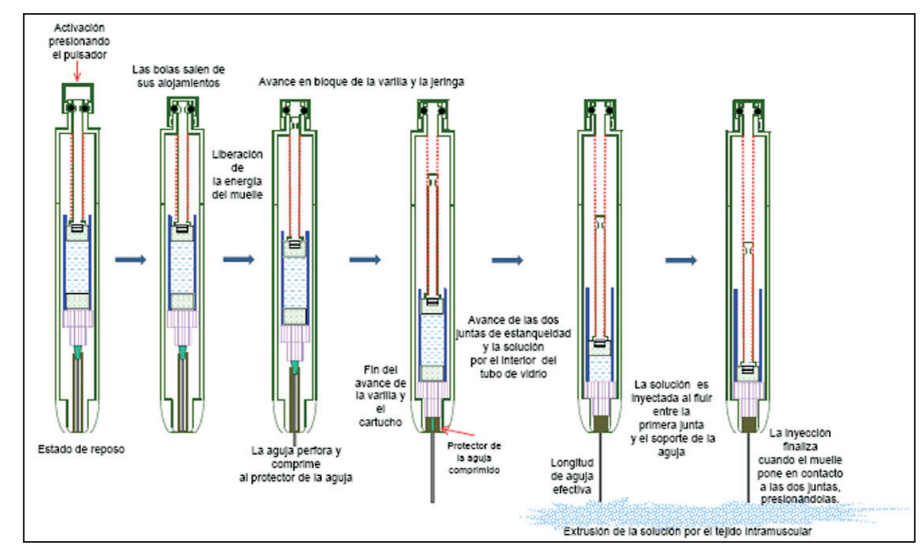

Figura 3. Dinámica de funcionamiento del Autoinyectable de Atropina-Oxima DEF. 


\section{JJ. Sánchez Ramos}

como a un movimiento físico extremo que simula una situación de estrés de campaña (carrera continua, campo a través; portabilidad). En el ensayo de resistencia a la caída, cada AI de una muestra $(n=20)$ se somete a un triple ensayo de caída libre desde una altura de un metro sobre una superficie de hormigón. En el primer ensayo, el AI impacta en posición horizontal; en el segundo se deja caer perpendicularmente al suelo impactando con el extremo de inyección; en el tercero se deja caer sobre el extremo opuesto. Posteriormente, cada AI es examinado y activado, determinándose la fuerza de activación, la longitud de aguja efectiva, el tiempo de autoinyección, y el volumen descargado (performances).

\section{Ensayo de resistencia a la carga estática}

Cada AI $(n=10)$ fue sometido a una carga estática de $400 \mathrm{~N}$ (equivalentes a $40 \mathrm{~kg}$ de peso) durante 24 horas $^{25}$. Posteriormente, cada AI fue examinado y se llevaron a cabo las determinaciones del apartado anterior.

\section{Ensayo de resistencia a la portabilidad}

El AI fue fijado por encima del tobillo de corredores voluntarios que lo portaron durante $12 \mathrm{Km}$ de carrera continua campo a través durante una hora, en una simulación de estrés físico en campaña. Posteriormente se comprobó sus performances.

\section{Tratamiento estadístico}

Para cada resultado se expresa el valor promedio y, a partir de la desviación estándar de la población, los límites tipificados para un 95 por ciento de confianza $(p=0,95 ; \alpha=0,05)^{26}$. Se expresa también la desviación estándar relativa (RSD).

\section{Diseño de nuevos autoinyectables}

Mediante un programa de ACAD, y con los mismos componentes caracterizados, se han fijado aquellas variables de diseño que son función de las propiedades galénicas de cada solución inyectable. Definen la posición de la junta superior, posición relativa del tubo de vidrio respecto a la varilla, y longitud total de la pieza de inyección, manteniendo constante los restantes parámetros.

\section{RESULTADOS}

\section{Desarrollo y presentación del Autoinyectable AJP}

En las Figuras 1, 2 y 3 se presentan, como resultado del largo proceso de I+D que se lleva a cabo en el CEMILFARDEF, los componentes diseñados, la jeringa específicamente desarrollada, el Autoinyectable de atropina-oxima DEF obtenido, y su dinámica de funcionamiento.

\section{Autoinyector AJP}

Resultado del trabajo realizado entre los años 1.991 y 1.995 , el Autoinyector de Jeringas Prellenadas (AJP) se registra en la Oficina Española de Patentes y Marcas con la patente número $9102545 / 2055648^{27}$. Su evolución da como resultado final al AI que se fabrica desde 2006, que se presenta en este trabajo. Está formado por cuatro piezas fabricada en material plástico $A B B^{R}$ (alta resistencia al impacto), una varilla de duraluminio, un muelle helicoidal a compresión rectificado y fabricado en acero inoxidable AISI 302 templado, y cuatro bolas de precisión de acero al carbono C-500 cromado. En la Figura 1 se han señalado sus tres zonas funcionales.

La zona I comprende el mecanismo de activación, con cuatro bolas de precisión que, en sus alojamientos en la pieza base del mecanismo de disparo, bloquean el avance de la varilla guía del muelle y soporte de la jeringa. La varilla es un componente esencial en la dinámica de funcionamiento del AI por intervenir en el mecanismo de disparo (bloqueo de las bolas), y actuar como guía del muelle y soporte de la jeringa, fijando a ambos componentes en posición tanto en reposo como en las diferentes etapas tras la activación (Figura 1).

En la zona II se encuentra el muelle, que aporta la fuerza motora para el funcionamiento del AI. Está alojado y comprimido entre la pieza base del mecanismo de disparo y la varilla, gracias la bloqueo ejercido por las cuatro bolas. Por su extremo opuesto la varilla está diseñada para roscar directamente sobre el émbolo de la jeringa, que de esta forma queda fijada en posición y centrada en el interior del AI. De las propiedades del muelle depende la sucesión de etapas que se desencadenan tras presionar el pulsador de activación, cualquiera que sea la orientación del AI. Su fuerza se ha optimizado y equilibrado en un rango de valores bajo control para un tiempo de inyección mínimo, y un funcionamiento seguro y eficaz. Una fuerza excesiva puede producir tras la activación un impacto de la jeringa sobre el final de su recorrido en el interior del AI superior al que puede resistir, provocando la rotura del tubo de vidrio. Así mismo, una fuerza excesiva puede crear una alta presión en la solución contenida en el cuerpo de vidrio provocando su estallido o su fuga por la unión entre la junta de estanqueidad y el tubo de vidrio, o entre este y el soporte de la aguja. Por el contrario, una fuerza del muelle insuficiente puede no completar la secuencia de acciones necesarias para llevar a cabo la inyección de la solución, especialmente en las etapas más críticas, como es el desplazamiento de la junta de estanqueidad por el tubo de vidrio de la jeringa, y la descarga de las últimas porciones de solución. En el intervalo de fuerzas idóneo, el muelle confiera al dispositivo una alta velocidad de inyección, aún después de largos periodos de almacenamiento. Por otro lado, se ha comprobado que la fuerza activación a aplicar sobre el pulsador para disparar el autoinyectable está relacionada con la fuerza del muelle, al ser responsable del bloqueo entre pulsador, bolas, varilla y pieza base del mecanismo de disparo (Figura 1). En el intervalo idóneo, a menor fuerza del muelle, menor fuerza de activación.

La pieza de inyección constituye la zona III del AI (Figura 1), y está diseñada interiormente con dos diámetros internos fundamentales para su correcto funcionamiento $\left(\mathrm{d}_{1}, \mathrm{~d}_{2}\right)$. Se ajusta mediante rosca a la pieza del mecanismo de disparo, y presen- 


\section{Estudio y caracterización del Autoinyectable de atropina-oxima DEF. Diseño de nuevos ...}

ta forma cónica coronada por el orificio de salida de la aguja. En reposo, el orificio queda ocluido interiormente por el protector de la aguja.

\section{El cartucho o jeringa prellenada (Figura 1)}

Es otro componente crítico para el AI por las propiedades físicas (resistencia mecánica), químicas (inercia) y biológicas (esterilidad) que ha de reunir como envase primario de la solución inyectable, y por el estrés mecánico a que puede verse sometido, tanto en su portabilidad, como en la dinámica de funcionamiento. Está formado por un tubo de vidrio de primera clase hidrolítica ${ }^{19}$ como cuerpo principal del cartucho, al que se acoplan dos juntas de estanqueidad o émbolos fabricados en un elastómero de grado farmacéutico, para formar el envase primario del medicamento inyectable. Durante su vida útil, a diferencia de otros AI, no existe contacto de la solución con la aguja, ni con partes metálicas que catalicen reacciones de descomposición, lo que constituye una garantía de estabilidad. La pieza de plástico soporte de la aguja, fabricada en polipropileno, hace también de vía de paso de la solución en el momento de la autoinyección. La aguja es estándar y mantiene su esterilidad mediante el protector, fabricado con un elastómero termoplástico muy flexible y diseñado para ajustar elásticamente sobre el cono luer de la misma. El extremo libre del protector presenta interiormente un conducto capilar donde queda alojada la aguja, y le sirve de guía en su salida tras la activación. El diámetro del protector es superior al del orifico de salida en la pieza de inyección, y tras el disparo es perforado por la aguja, quedando comprimido en el interior del AI.

Para garantizar la integridad física de la jeringa durante el impacto del disparo, y su estanqueidad ante la alta presión durante la descarga, una funda de plástico tubular tipo sleever que se retrae por calor, enfaja y da fortaleza al conjunto formado por el tubo de vidrio y el soporte de la aguja.

\section{Autoinyectable de Atropina-Oxima DEF (AI-AOD)}

Es una de las 97 presentaciones de la relación de medicamentos fabricados por los Servicios Farmacéuticos del Ministerio de Defensa Español ${ }^{28}$, con número OTAN de Codificación - N.O.C.650533 0051675, y Código Nacional -C.N.- número 698712. Está indicado en el tratamiento de la exposición a agentes nerviosos (neurotóxicos). Contiene $2 \mathrm{mg}$ de sulfato de atropina como antimuscarínico, y $600 \mathrm{mg}$ de cloruro de pralidoxima como reactivador de la acetilcolinesteras, en $3 \mathrm{ml}$ de solución inyectable. Dos bandas normalizadas en amarillo y marrón codifican a ambos antídotos. El $A I-A O D$ forma parte de la dotación de medicamentos de las Fuerzas Armadas Españolas, tanto en territorio nacional como en sus misiones internacionales. Ha sido suministrado a las Fuerzas y Cuerpos de Seguridad Nacional, y a varios países de nuestro entrono.

La administración se lleva a cabo en tres etapas: 1.- Retirar el tapón protector del pulsador de autoinyección, girándolo por la línea microperforada de la etiqueta. 2.- Apoyar el extremo de autoinyección sobre la cara antero-lateral del muslo. 3.- Presionar con el dedo pulgar el pulsador de autoinyección. La inyección se produce de forma automática en no más de cinco segundos. En la Figura 3 se expone su dinámica de funcionamiento. Como resultado final, se produce la extrusión de la solución por el tejido intramuscular hasta que finalmente las dos juntas quedan alojadas en la pieza soporte de la aguja y presionadas aún con firmeza por el muelle. La solución en el interior de la jeringa estará agotada. La fuerza residual del muelle evita el retroceso de la aguja y del cartucho.

\section{Caracterización del autoinyectable y sus componentes}

En la Tabla 2 se exponen los resultados obtenidos en la caracterización del autoinyectable y sus componentes.

Tabla 2. Resultados de la caracterización del Autoinyector AJP, su jeringa prellenada y el Autoinyectable de atropina-oxima DEF

\begin{tabular}{|c|c|c|}
\hline & Resultados & Variabilidad \\
\hline Peso: & $69,3376 \mathrm{~g} \pm 0,4361 \mathrm{~g}$ & $\begin{array}{c}\mathrm{p}=0,95 ; \mathrm{n}=460 \\
\mathrm{RSD}=0,32 \%\end{array}$ \\
\hline Longitud: & $199,98 \mathrm{~mm} \pm 0,05 \mathrm{~mm}$ & $\begin{array}{c}\mathrm{p}=0,95 ; \mathrm{n}=20 \\
\mathrm{RSD}=0,013 \%\end{array}$ \\
\hline Diámetro: & $22,4754 \mathrm{~mm} \pm 0,1 \mathrm{~mm}$ & $\begin{array}{c}\mathrm{p}=0,95 ; \mathrm{n}=20 \\
\mathrm{RSD}=0,23 \%\end{array}$ \\
\hline $\begin{array}{l}\text { Volumen descarga } \\
\text { real }\end{array}$ & $2,719 \mathrm{ml} \pm 0,024 \mathrm{~m}$ & $\begin{array}{c}\mathrm{p}=0,95 ; \mathrm{n}=280 \\
\mathrm{RSD}=0,45 \%\end{array}$ \\
\hline $\begin{array}{l}\text { Contenido descarga: } \\
\text { Sulfato de atropina }\end{array}$ & $1,994 \pm 0,018 \mathrm{mg}$ & $\begin{array}{c}\mathrm{p}=0,95 ; \mathrm{n}=280 \\
\mathrm{RSD}=0,46 \%\end{array}$ \\
\hline $\begin{array}{l}\text { Cloruro de } \\
\text { pralidoxima }\end{array}$ & $598,78 \pm 5,304 \mathrm{mg}$ & $\begin{array}{c}\mathrm{p}=0,95 ; \mathrm{n}=280 \\
\mathrm{RSD}=0,45 \%\end{array}$ \\
\hline $\begin{array}{l}\text { Endotoxinas } \\
\text { bacterianas }\end{array}$ & $<0,250 \mathrm{EU} / \mathrm{ml}$ & No procede \\
\hline Fuerza de activación & $48,80 \pm 6,75 \mathrm{~N}$ & $\begin{array}{c}\mathrm{p}=0,95 ; \mathrm{n}=20 \\
\mathrm{RSD}=7,05 \%\end{array}$ \\
\hline Tiempo salida aguja & $<0,10 \mathrm{~s}$ & No procede \\
\hline $\begin{array}{l}\text { Tiempo de } \\
\text { autoinyección }\end{array}$ & $1,38 \pm 0,22 \mathrm{~s}$ & $\begin{array}{c}\mathrm{p}=0,95 ; \mathrm{n}=20 \\
\mathrm{RSD}=8,10 \%\end{array}$ \\
\hline $\begin{array}{l}\text { Longitud aguja } \\
\text { efectiva }\end{array}$ & $26,23 \mathrm{~mm} \pm 0,89 \mathrm{~mm}$ & $\begin{array}{c}\mathrm{p}=0,95 ; \mathrm{n}=20 \\
\mathrm{RSD}=1,73 \%\end{array}$ \\
\hline Dosis descargadas & $2,719 \mathrm{ml} \pm 0,024 \mathrm{ml}$ & $\begin{array}{c}\mathrm{p}=0,95 ; \mathrm{n}=280 \\
\mathrm{RSD}=0,45 \%\end{array}$ \\
\hline $\begin{array}{l}\text { Resistencia caída } \\
\text { libre ( } 3 \text { caídas } \\
\text { en diferentes) } \\
\text { posiciones): }\end{array}$ & Resistente & $\mathrm{n}=20$ \\
\hline $\begin{array}{l}\text { Resistencia carga } \\
\text { estática (400N/24h): }\end{array}$ & Resistente & $\mathrm{n}=20$ \\
\hline $\begin{array}{l}\text { Resistencia carrera } \\
\text { continua } 12 \mathrm{~km}- \\
60 \mathrm{~min} .\end{array}$ & Resistente & $\mathrm{n}=20$ \\
\hline \multicolumn{3}{|l|}{ Muelle } \\
\hline Longitud inicial & $140 \pm 0,82 \mathrm{~mm}$ & $\begin{array}{c}\mathrm{p}=0,95 ; \mathrm{n}=20 \\
\mathrm{RSD}=0,30 \%\end{array}$ \\
\hline Diámetro exterior & $10,7 \mathrm{~mm}$ & \\
\hline Diámetro interior & $8,1 \mathrm{~mm}$ & \\
\hline
\end{tabular}




\section{JJ. Sánchez Ramos}

\begin{tabular}{|c|c|c|}
\hline & Resultados & Variabilidad \\
\hline Número de espiras & 33 vueltas & \\
\hline $\begin{array}{l}\text { Diámetro del hilo } \\
\text { metálico }\end{array}$ & $1,3 \mathrm{~mm}$ & \\
\hline $\begin{array}{l}\text { Longitud muelle } \\
\text { comprimido }\end{array}$ & $51 \mathrm{~mm}$ & \\
\hline $\begin{array}{l}\text { Longitud muelle en } \\
\text { AI tras activación }\end{array}$ & $119,75 \mathrm{~mm} \pm 1,59 \mathrm{~mm}$ & $\begin{array}{l}\mathrm{p}=0,95 ; \mathrm{n}=6 \\
\mathrm{RSD}=0,67 \%\end{array}$ \\
\hline $\begin{array}{l}\text { Fuerza residual tras } \\
\text { la descarga }\end{array}$ & $18,21 \pm 1,51 \mathrm{~N}$ & $\begin{array}{l}\mathrm{p}=0,95 ; \mathrm{n}=6 \\
\mathrm{RSD}=4,23 \%\end{array}$ \\
\hline $\begin{array}{l}\text { Longitud muelle } \\
\text { libre tras activación }\end{array}$ & $132,14 \pm 0,83 \mathrm{~mm}$ & $\begin{array}{c}\mathrm{p}=0,95 ; \mathrm{n}=20 \\
\mathrm{RSD}=0,32 \%\end{array}$ \\
\hline \multicolumn{3}{|l|}{$\begin{array}{l}\text { Jeringa prellenada } \\
\text { AJP }\end{array}$} \\
\hline $\begin{array}{l}\text { Peso de la jeringa } \\
\text { prellenada }\end{array}$ & $13,3875 \pm 0,1266 \mathrm{~g}$ & $\begin{array}{c}(\mathrm{p}=0,95 ; \mathrm{n}=370 \\
\mathrm{RSD}=0,48 \%)\end{array}$ \\
\hline \multicolumn{3}{|l|}{$\begin{array}{l}\text { Fuerzas con una } \\
\text { sola JE en el CVJ: }\end{array}$} \\
\hline $\begin{array}{l}\text { Fuerza inicio } \\
\text { desplazamiento }\end{array}$ & $3,30 \pm 1,84 \mathrm{~N}$ & $\begin{array}{l}\mathrm{p}=0,95 ; \mathrm{n}=6 \\
\mathrm{RSD}=28,45 \%\end{array}$ \\
\hline $\begin{array}{l}\text { Fuerza máx. } \\
\text { desplazamiento }\end{array}$ & $10,35 \pm 8,02 \mathrm{~N}$ & $\begin{array}{l}p=0,95 ; n=6 \\
R S D=39,53 \%\end{array}$ \\
\hline \multicolumn{3}{|l|}{$\begin{array}{l}\text { Fuerzas con dos JE } \\
\text { y solución en el CVJ }\end{array}$} \\
\hline $\begin{array}{l}\text { Fuerza inicio } \\
\text { desplazamiento }\end{array}$ & $6,83 \pm 6,55 \mathrm{~N}$ & $\begin{array}{l}\mathrm{p}=0,95 ; \mathrm{n}=6 \\
\mathrm{RSD}=48,93 \%\end{array}$ \\
\hline $\begin{array}{l}\text { Fuerza máx. } \\
\text { desplazamiento }\end{array}$ & $16,60 \pm 13,48 \mathrm{~N}$ & $\begin{array}{l}\mathrm{p}=0,95 ; \mathrm{n}=6 \\
\mathrm{RSD}=41,43 \%\end{array}$ \\
\hline
\end{tabular}

$\mathrm{RSD}=$ Desviación estándar relativa (\% respecto al promedio)

\section{Desarrollo de fuerzas del muelle del autoinyectable en los cuartiles de compresión}

En la Figura 4 se exponen las fuerzas promedio disponibles en función del porcentaje de compresión al que se encuentra sometido el muelle en el autoinyectable. Se ha asignando el valor $0 \%$ de compresión a la posición de reposo del muelle, y el valor $100 \%$ de compresión a la posición final en el AI.

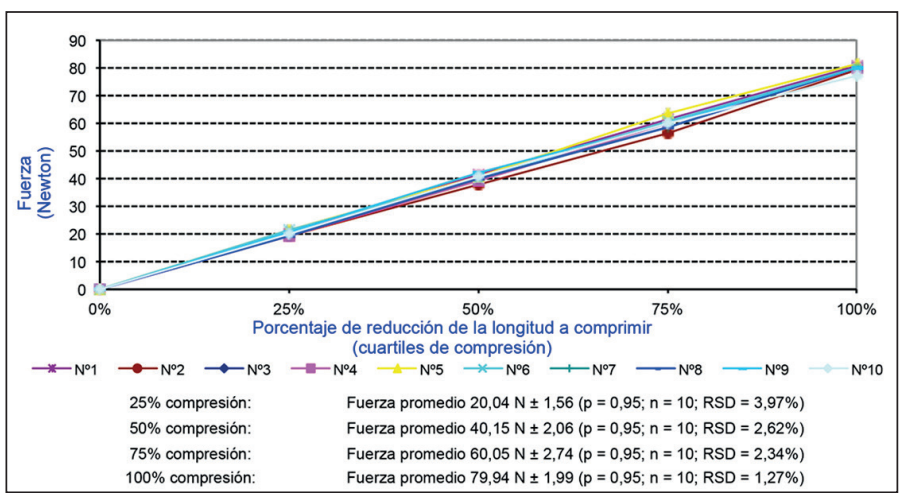

Figura 4. Desarrollo de fuerzas en los cuartiles de compresión del muelle $(n=10)$ del Autoinyectable de Atropina-Oxima DEF.

\section{Fuerza del muelle disponible tras la activación del autoinyectable}

Para obtención de esta fuerza, esencial en la dinámica de funcionamiento, la longitud inicial del muelle (140 $\pm 0,82 \mathrm{~mm}$; $\mathrm{p}=0,95 ; \mathrm{n}=20 ; \mathrm{RSD}=0,30 \%)$ se reduce a la longitud de diseño en la varilla $(51 \mathrm{~mm})$. La fuerza óptima resultante de esta compresión, determinada experimentalmente, es $80 \mathrm{~N}(79,94 \pm$ $1,99 \mathrm{~N} ; \mathrm{p}=0,95 ; \mathrm{n}=10$; RSD $=1,27 \%$ ). Muelles con fuerza de $120 \mathrm{~N}$ produjeron entre $10-20$ por ciento de descargas defectuosas, bien por roturas del vidrio como consecuencia del fuerte impacto, o por pérdidas de solución ocasionadas por la alta presión sobre el líquido en la jeringa. Por el contrario, muelles con fuerzas inferiores a $80 \mathrm{~N}$ no completaron la inyección, al no vencer la resistencia en puntos críticos en la dinámica de funcionamiento.

\section{Fuerza residual del muelle en el autoinyectable tras la descarga de la jeringa}

El muelle aún sigue manteniendo un cierto grado de compresión que da lugar a un promedio de fuerza final remanente de $18,21 \mathrm{~N} \pm 1,51 \mathrm{~N}(\mathrm{p}=0,95 ; \mathrm{n}=6$; $\mathrm{RSD}=4,23 \%)$. Radica en la reducción de su longitud inicial a la longitud disponible en el AI para el muelle tras el disparo $(119,75 \mathrm{~mm} \pm 1,59 \mathrm{~mm}$; $\mathrm{p}=0,95 ; \mathrm{n}=6 ; \mathrm{RSD}=0,67 \%)$. Estos resultados contemplan el acortamiento por deformación que sufre el muelle por compresión. Se ha observado que el acortamiento por deformación no depende del tiempo que el muelle permanece comprimido, sino que es una deformación intrínseca y característica de su material constitutivo. Para el muelle del $A I-A J P$, con una longitud inicial de $140 \mathrm{~mm}$, resultó una longitud promedio tras la activación de $132,14 \mathrm{~mm} \pm 0,83 \mathrm{~mm}(\mathrm{p}=0,95 ; \mathrm{n}=20 ; \mathrm{RSD}=0,32 \%)$, y un acortamiento del 5,6\% de su longitud inicial.

\section{Defectos físicos en el vidrio}

Los tubos de vidrio utilizados en la fabricación del $A I-A J P$ carecen de microfisuras, deslaminados y zonas de tensión en el vidrio. Se inspecciona el 100\% del material de partida.

\section{Friabilidad}

Los resultados de este ensayo de resistencia mecánica sobre muestras representativas de tubos de vidrio de la jeringa, correctamente fabricados e inspeccionados, fueron satisfactorios.

\section{Siliconado de los tubos de vidrio de la jeringa}

De los diferentes procedimientos ensayados, la inmersión de los tubos de vidrio en una emulsión de dimeticona al 2\% en agua para inyectables, realizada entre los procesos de lavado y secado automático, fue el procedimiento de elección por los resultados de inyectabilidad obtenidos (Figura 5) y por la facilidad de ejecución del procedimiento. 
Estudio y caracterización del Autoinyectable de atropina-oxima DEF. Diseño de nuevos ...

\section{Inyectabilidad}

Las fuerzas necesarias para el desplazamiento de los émbolos por el tubo de vidrio de la jeringa son inversamente proporcionales a la idoneidad del procedimiento de siliconado. El perfil de fuerzas tiene un pico inicial que se corresponde con la breakloose force y pone de manifiesto variaciones en la lubricación. El valor máximo es usado como estimación del peor caso. Para soluciones de baja viscosidad como las estudiadas, la fuerza de fricción es el factor determinante del tiempo de inyección, y aquí, el cuerpo de vidrio y las juntas son rigurosamente caracterizados.

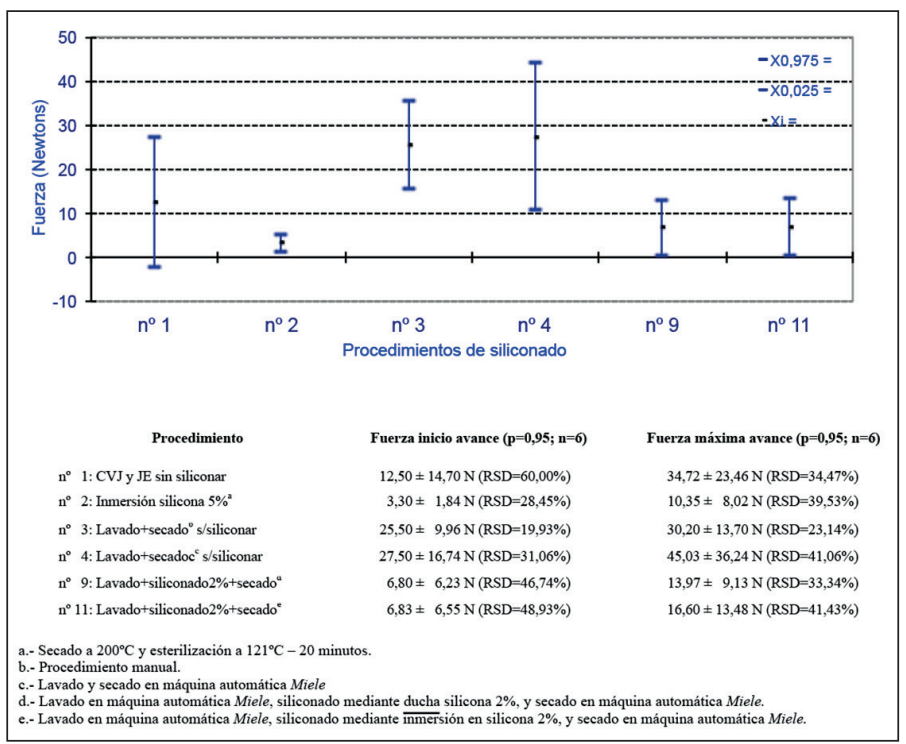

Figura 5. Inyectabilidad. Fuerza para iniciar el avance del émbolo ( $J E$ ) en el tubo de vidrio (CVJ) del Autoinyectable AJP, en función del procedimiento de siliconado.

Se determinaron, en primer lugar, las fuerzas necesarias para el inicio y la continuidad del desplazamiento de «una sola junta» por el cuerpo de vidrio de la jeringa vacío, para cada procedimiento de siliconado. Los resultados se exponen en la Figura 5, siendo el procedimiento descrito en el apartado anterior el que presentó los valores del promedio de fuerzas más bajo, tanto para iniciar el desplazamiento $(3,30 \pm 1,84 \mathrm{~N} ; \mathrm{p}=0,95 ; \mathrm{n}=6 ; \mathrm{RSD}=28,45 \%)$ como en el valor máximo registrado para mantenerlo $(10,35 \pm 8,02 \mathrm{~N}$; $\mathrm{p}=0,95 ; \mathrm{n}=6$; RSD $=39,53 \%)$. En segundo lugar, se determinaron las fuerzas para iniciar y mantener el avance del conjunto de las «dos juntas con la solución inyectable en la jeringa equipada con su aguja». Según se expone en la Figura 5 , estas fuerzas disminuyen considerablemente con la idoneidad del procedimiento de siliconado, pasando la fuerza para el inicio de desplazamiento de valores superiores a $30 \mathrm{~N}$ con tubos sin siliconar, a un promedio de 6,83 $\pm 6,55 \mathrm{~N}$ ( $\mathrm{p}=0,95$; $\mathrm{n}=6$ ) con los tubos siliconados. Así mismo, una vez iniciado el desplazamiento, las fuerzas máximas registradas con tubos de vidrio sin siliconar fueron superiores a $40-60 \mathrm{~N}$, mientras que para los tubos siliconados mediante el procedimiento seleccionado fue de $16,60 \pm 13,48 \mathrm{~N}(\mathrm{p}=0,95 ; \mathrm{n}=6)$.

\section{Esterilidad}

Los ensayos de esterilidad sobre materiales de partida, producto intermedio y terminado, fueron negativos.

\section{Pirógenos}

La solución descargada del AI es apirógena (menos de 0,250 unidades estándar de endotoxina por mililitro).

\section{Inercia química}

Los materiales plásticos y elastómeros ensayados cumplen los requerimientos más exigentes (farmacopea Tipo I).

\section{Contenido de la solución autoinyectable}

El contenido promedio de cloruro de pralidoxima en $3 \mathrm{ml}$ de solución inyectable fue de $671,23 \mathrm{mg} \pm 22,01 \mathrm{mg}(\mathrm{p}=0,95 ; \mathrm{n}=$ 16 lotes; RSD $=1,67 \%$ ), que corresponde a un porcentaje promedio del $111,87 \% \pm 3,68 \%$ del contenido nominal o etiquetado (600 mg en $3 \mathrm{ml}$ ), y un 101,70 $\pm 3,33 \%$ respecto al contenido teórico descargado $(2,727 \mathrm{ml})$.

\section{Estabilidad de la solución}

El periodo de caducidad del $A I-A O D$ es cinco años. El reanálisis de autoinyectables fabricados en los últimos diez años confirma que, tanto el dispositivo como la solución mantienen sus especificaciones en un amplio rango de temperatura $\left(2^{\circ}-35^{\circ} \mathrm{C}\right)$. No se detectó cambio de coloración, ni partículas en la solución $^{29}$. Por otro lado, en los últimos tres años se estudia, con resultados satisfactorios, la estabilidad de las soluciones inyectables envasadas en las jeringas de los nuevos AI diseñados: Atropina, Diazepam, Morfina, Multicomponentes y Epinefrina.

\section{Contaje de partículas en la solución descargada del autoinyectable}

Los valores promedio obtenidos de muestras de 23 lotes de fabricación $(p=0,95)$ para ocho tamaños de partícula, se muestran en la Figura 6. Los resultados fueron muy inferiores a los límites especificados en farmacopea: 6.000 partículas de $10 \mu$ por jeringa y 300 partículas de $25 \mu$ por jeringa [2.9.19. Eur. Ph. $]^{18}$, límites máximos que corresponden a 2.000 y 100 partículas por mililitro, respectivamente. El siliconado no incrementa el contaje de partículas respecto a la misma solución sin envasar, en tamaños superiores a $10 \mu$.

\section{Peso del Autoinyectable de atropina-oxima DEF}

En el control de peso de 460 unidades muestreadas de un total de 18.000 AI fabricados en 7 lotes de producción, el peso 


\section{JJ. Sánchez Ramos}

promedio fue $69,3376 \pm 0,4361$ gramos $(\mathrm{p}=0,95 ; \mathrm{n}=460$; $\mathrm{RSD}=0,32 \%)$.

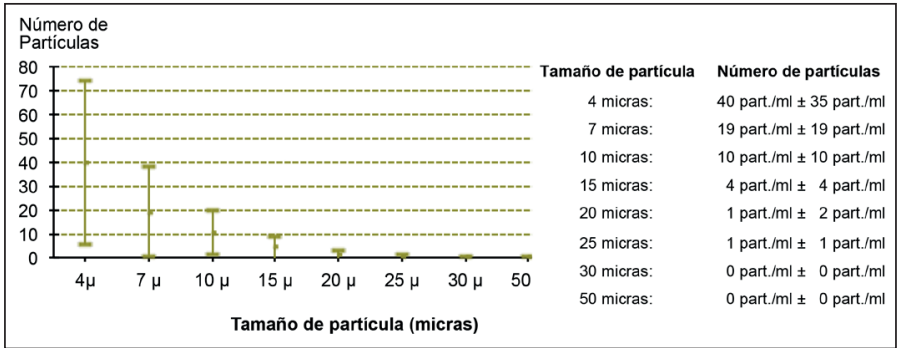

Figura 6. Contaje de partículas en la solución descargada del Autoinyectable de atropina-oxima DEF. Valores promedio de 23 lotes de producción, con un intervalo de confianza del 95\%

\section{Peso de la jeringa prellenada}

En el control de peso de 370 jeringas prellenadas muestreadas de un total de 18.000 fabricadas en 6 lotes de producción, el peso promedio fue 13,3875 $\pm 0,1266$ gramos $(\mathrm{p}=0,95 ; \alpha=0.05 ; \mathrm{n}=370$; $\mathrm{RSD}=0,48 \%$ ). El estudio de la variabilidad de los resultados entre los AI y las jeringas revela que, aunque la variabilidad de peso dentro de cada lote es de pequeña magnitud, para los AI la variabilidad entre los diferentes lotes es mayor que para las jeringas, por la mayor variabilidad de peso de los componentes plásticos y metálicos del AI.

\section{Fuerza de activación}

En la Figura 7 se representan los resultados de la fuerza a aplicar sobre el pulsador de activación para provocar el disparo del AI. El valor promedio fue 48,80 \pm 6,75 Newton $(\mathrm{p}=0,95 ; \mathrm{n}=20 ; \mathrm{RSD}=7,05 \%)$.

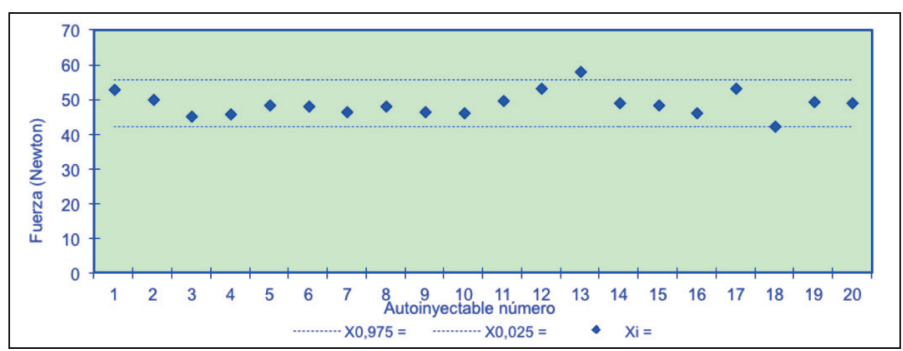

Figura 7. Fuerza de activación del Autoinyectable de atropinaoxima DEF. (Valor promedio 48,80 $\pm 6,75 N(p=0,95 ; n=20$; $R S D=7,06 \%)$.

\section{Tiempo de autoinyección}

Su determinación abarca la variabilidad de todos los componentes del AI. El promedio para el tiempo de descarga de la solución fue de 1,38 $\pm 0,22$ segundos $(\mathrm{p}=0,95 ; \mathrm{n}=20 ; \mathrm{RSD}=$ $8,10 \%)$, y fue independiente de la posición en la que se coloque el AI durante su activación y descarga, y de la temperatura en el rango entre $0^{\circ}$ a $40^{\circ} \mathrm{C}$. El tiempo de salida de la aguja fue inferior a diez centésimas de segundo.

\section{Longitud de aguja efectiva}

El valor promedio tras la activación (Figura 8) fue 26,23 \pm $0,89 \mathrm{~mm}(\mathrm{p}=0,95 ; \mathrm{n}=20 ; \mathrm{RSD}=1,73 \%)$. La activación a través de tejido vaquero tipo Lewis, o con el AI en cualquier posición, no alteró la longitud de aguja efectiva, ni las características de la aguja, ni de la inyección.

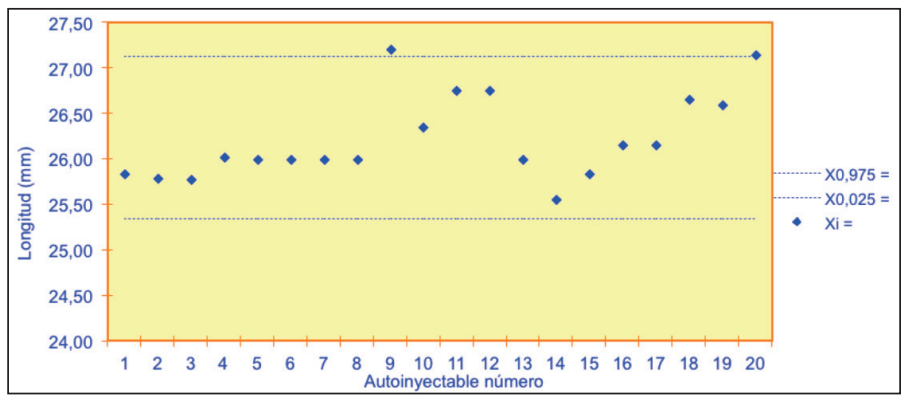

Figura 8. Longitud de aguja efectiva del Autoinyectable de atropina-oxima DEF. (Valor promedio 26,23 $\mathrm{mm} \pm 0,89 \mathrm{~mm}(p=0,95$; $n=20 ; R S D=1,73 \%)$.

\section{Dosis descargada tras la activación}

Las dosis medias descargadas tras la activación de $20 \mathrm{AI}$ de cada uno de los 14 lotes muestreados $(\mathrm{n}=280)$ dio un peso promedio de $2,847 \mathrm{~g} \pm 0,025 \mathrm{~g}(\mathrm{p}=0,95 ; \mathrm{n}=280 ; \mathrm{RSD}=0,46 \%)$ equivalente a un volumen de $2,719 \mathrm{ml} \pm 0,024 \mathrm{ml}(\mathrm{p}=0,95 ; \mathrm{n}=$ 280 ; RSD $=0,45 \%$ ). Los promedios de sulfato de atropina y cloruro de pralidoxima descargados fueron, respectivamente, 1,994 $\pm 0,018 \mathrm{mg}$ y $598,78 \pm 5,304 \mathrm{mg}(\mathrm{p}=0,95 ; \mathrm{n}=280)$, lo que supone un $99,7 \%$ del contenido etiquetado.

\section{Resistencia}

Los AI ensayados $(n=20)$ resistieron sin incidencias el triple ensayo de caída libre. La activación posterior a los impactos presentó valores de fuerza de activación, longitud de aguja, tiempo de autoinyección y volumen descargado, dentro de los intervalos de confianza obtenidos para cada parámetro en condiciones normales. Los resultados obtenidos para estos mismos parámetros tras la activación y descarga de las muestras sometidas a los ensayos de Resistencia a la carga estática y Resistencia a la carrera continua estuvieron también dentro de los intervalos de confianza obtenidos para los ensayos sin estrés físico previo.

\section{Diseño de nuevos autoinyectables}

En la Figura 9 se exponen los resultados para las variables de diseño de los diferentes componentes del AI en función del volumen de solución que corresponde a su indicación. Se han ensayado con éxito prototipos para cada una de las cinco formulaciones bajo estudio. En la Figura 10 se muestra el diseño final de los cinco nuevos AI para Defensa NBQ y medicaciones de urgencia. 
Estudio y caracterización del Autoinyectable de atropina-oxima DEF. Diseño de nuevos ...

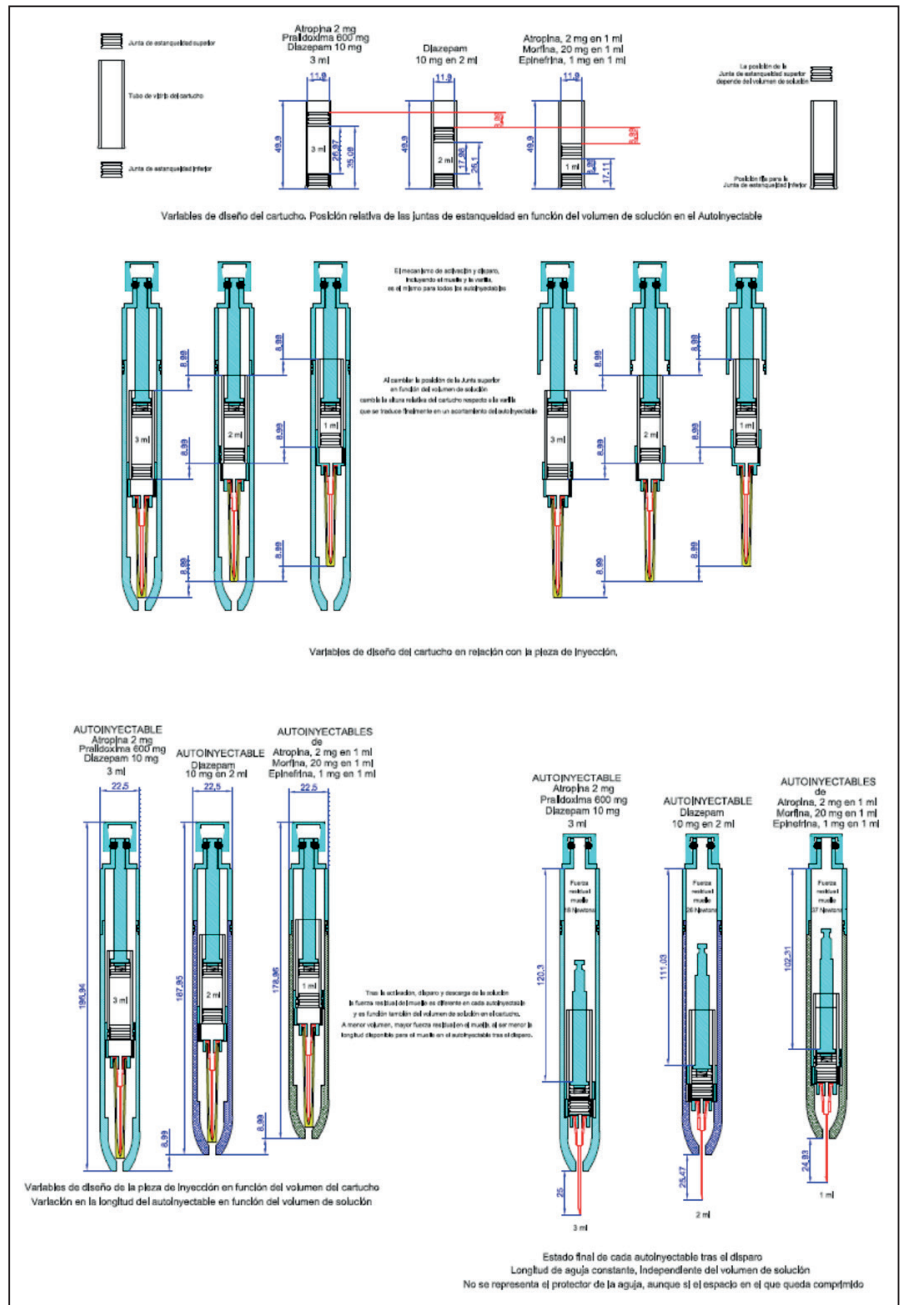

Figura 9. Diseño y desarrollo de nuevos autoinyectables para Defensa NBQ y otros medicamentos de urgencia.

\section{DISCUSIÓN}

La falta de ensayos y criterios de valoración oficialmente consensuados y publicados en las farmacopeas para la fabricación y uso de los $\mathrm{AI}^{25}$, ha obligado a definir los atributos y variables que se consideran críticos, en base al estado actual de la ciencia y a la experiencia adquirida. Los resultados obtenidos, y la recopilación de información técnica disponible tras años en servicio, ponen de manifiesto que el $A I-A J P$ constituye un dispositivo de autoinyección robusto y consistente, especialmente en su aplicación militar en Defensa NBQ. La autoinyección es segura, eficaz y carente de errores. Con estos objetivos como condición, se han estudiado las características del Autoinyector AJP, su jeringa específicamente desarrollada, y el $A I-A O D$. Siendo satisfactorios los resultados obtenidos, el diseño de estos componentes puede ser fácilmente extrapolado y adaptado a otros medicamentos AI de urgencia vital (atropina, diazepam, morfina, epinefrina, entre otros) dado el amplio rango de volúmenes y concentraciones que pueden ser presentados en el $A I-A J P$. Con ello están disponibles nuevos AI recomendados por la doctrina sanitaria $^{3}$ (Figura 9 y 10).

El éxito de un AI radica, además de en su calidad, seguridad y eficacia, en la instrucción de cada individuo del grupo de riesgo sobre todos los aspectos relacionados con su uso. El
AI-AJP es user-friendly. El primer aspecto a resaltar es su portabilidad. Se ha comprobado que sólo un $30 \%$ de las personas prescritas con un AI lo portaban ${ }^{8}$. Ante una situación de riesgo, cada individuo debe llevar siempre consigo al menos un AI. El peso y las dimensiones son factores de importancia en su portabilidad. Además, un tercio de las reacciones anafilácticas graves requieren más de una dosis de adrenalina autoinyectable ${ }^{1,30}$. Por otro lado, la actual doctrina en Defensa NBQ recomiendan que cada combatiente porte tres AI contra agentes nerviosos, administrando el primero en los 5 primeros minutos de la aparición de los signos de intoxicación, y nuevos AI cada 15 minutos si los signos persisten ${ }^{3,9}$. El $A I-A O D$ es ligero en peso. $\mathrm{Su}$ volumen se ha reducido a mínimos para garantizar una autoinyección consistente, y la robustez necesaria para un correcto funcionamiento y protección de su contenido, incluso en situaciones límite de estrés físico (golpes, caídas y estrés de campaña). Se trabaja en el diseño de un nuevo prototipo con volumen optimizado.

El adiestramiento es también esencial para una correcta administración por la ruta adecuada, en el momento oportuno, y bajo el estrés del ataque. Un panel de expertos ha concluido que, aún el más simple de los AI no es fácil de usar cuando el paciente está aislado e in extremis ${ }^{31}$. Se ha desarrollado un dispositivo de instrucción, que es una réplica del $A I-A J P$ sin aguja, para practicar la secuencia de etapas de la administración, aunque sin proporcionar la sensación real de la autoinyección. Se recomienda practicar el disparo de un AI real caducado sobre un tejido simulado, tal como una naranja ${ }^{24}$. Por su forma de lápiz, el $A I$ $A J P$ es intuitivo y predispone al paciente a un uso correcto, aun en la oscuridad (user-friendly). La forma tanto del protector de activación como del extremo de inyección induce a un solo sentido de administración. No son necesarias manipulaciones previas a la administración, ni se observan elementos relacionados con la inyección, con lo que es menor el factor psicológico negativo y la fobia generalizada hacia las agujas / inyecciones, que en el $8,2 \%$ de los casos es irrazonablemente intenso ${ }^{32}$, y puede llegar a incapacitar la administración.

Además de disponer de un AI en el momento oportuno (portabilidad), y saberlo utilizar correctamente (user-friendly), su funcionamiento debe estar carente de errores. Es un recur-

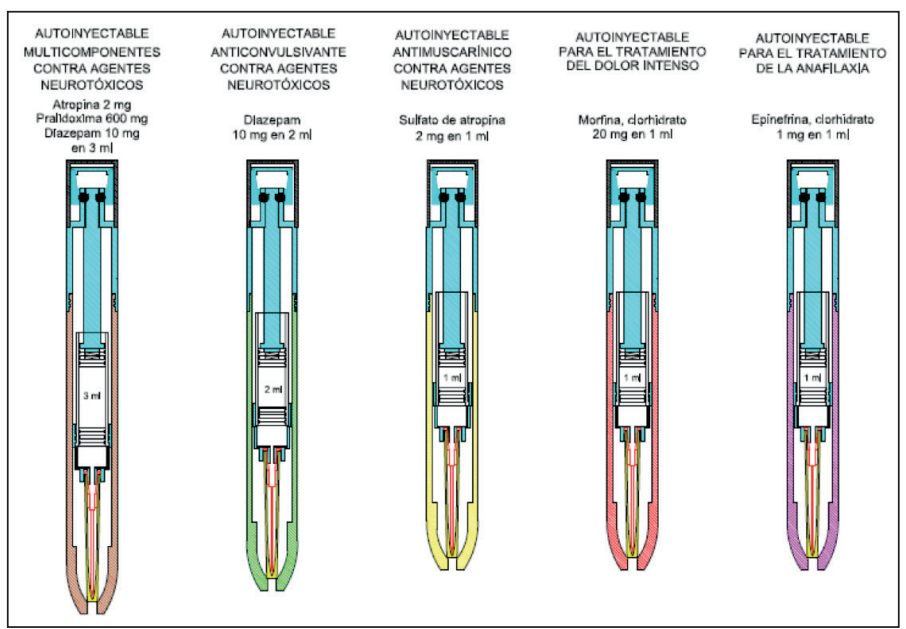

Figura 10. Nuevos autoinyectables para Defensa NBQ y otros medicamentos de urgencia. 


\section{JJ. Sánchez Ramos}

so vital, y su activación e inyección deben estar garantizadas. Se ha evaluado sin incidencias el funcionamiento de más de 500 $A I-A O D$. La seguridad del dispositivo tiene un impacto directo sobre la calidad de vida y la moral de los individuos de cada grupo de riesgo, que de otra manera constituiría una indefensión e intranquilidad ${ }^{9}$

Su empleo es sencillo. Para administrar el $A I-A J P$, basta retirar el protector de disparo mediante rotura de la línea micro-perforada que le une al resto del AI. La vista del pulsador de activación induce el modo de empleo, descrito e ilustrado en la superficie del AI en tres etapas que no han de ser memorizadas. El mecanismo de activación mediante pulsador simplifica su uso, y permite la autoinyección con una sola mano.

La ruta universalmente recomendada para la administración de los AI es la intramuscular, preferentemente en la cara antero-lateral del muslo ${ }^{33}$. Estudios realizados con epinefrina autoinyectable, revelan que los picos de concentración plasmática fueron significativamente más rápidos por vía intramuscular ( $8 \pm 2$ minutos) que por vía subcutánea $(34 \pm 14$ minutos $)^{34,35}$. El aumento de la obesidad en la población dificulta la liberación intramuscular del medicamento autoinyectable ${ }^{33}$, por lo que la longitud de aguja efectiva debe ser también suficiente para estos pacientes. Comparativamente, el $A I-A J P$ dispone de una mayor longitud de aguja efectiva ${ }^{25}$. Además, la profundidad de la autoinyección se ve favorecida por la fuerza que ejerce la mano y el dedo pulgar sobre el AI para activarlo, comprimiendo la ropa y el tejido subcutáneo, disminuyendo su espesor. Se ha comprobado que una fuerza de activación de $36 \mathrm{~N}$ reduce la distancia al músculo un $25 \%$ en mujeres y un $19 \%$ en hombres, por lo que el medicamento puede ser liberado respectivamente un $25 \%$ y un $19 \%$ más profundo ${ }^{36}$. La fuerza de activación del $A I$ - $A J P$ está comprendida entre 45-50 $\mathrm{N}$, lo que junto a una longitud de aguja efectiva superior a 26 $\mathrm{mm}$, un calibre de $0,9 \mathrm{~mm}$ y una adecuada fuerza de extrusión de la solución por el tejido, garantiza una inyección intramuscular consistente para un amplio rango de pacientes, incluso a través de la ropa de abrigo o del equipo de protección individual NBQ.

Por la dinámica de funcionamiento del Autoinyector AJP y la jeringa que contiene, no es posible la liberación del medicamento antes de que la aguja haya alcanzado el tejido diana. Sólo entonces es el medicamento liberado en el tejido intramuscular, y no antes $^{4}$. La inyección es prácticamente imperceptible por la alta velocidad de penetración de la aguja (menos de diez centésimas de segundo), por su afilado bisel, y por la presión aplicada durante la administración que reduce la sensibilidad de los receptores de la piel. El tiempo de inserción de la aguja es muy corto tras la activación, y la inyección de la solución muy rápida (menos de dos segundos). Aunque un paciente bien instruido debe mantener el AI en posición durante al menos 5 segundos después de la activación, el corto tiempo de inyección hace menos probable las pérdidas de medicamento motivadas por una retirada prematura del AI del punto de inyección.

Un factor negativo inherente al empleo de los AI es el riesgo de heridas producidas accidentalmente por el stick de la aguja, que normalmente queda expuesta tras la administración. El elevado número de casos reportados sugiere que es necesaria una instrucción adicional y un rediseño del dispositivo ${ }^{37,38}$. Se estudia la mejora de este aspecto en el $A I-A J P$, mediante un mecanismo de retracción de la aguja, o el rediseño del protector y del orificio de salida, de forma que al retirar el AI tras la administración, el protector comprimido recupere su forma original cubriendo el stick libre de la aguja.

Desde el punto de vista logístico-operativo militar el $A I$ - $A J P$ permite, por su diseño, mantener una reserva estratégica de autoinyectores durante largos periodos de tiempo sin las jeringas con las que deben estar equipados para producir el AI específco, evitando así la degradación y la caducidad del medicamento. Cuando sea necesario, es posible equipar el autoinyector con la jeringa prellenada de la solución inyectable del antídoto específico recién producida y en un corto plazo de tiempo, proporcionando un ahorro y flexibilidad no disponibles de otra manera. Así mismo, los AI no utilizados y caducados, son fácilmente reprocesados mediante sustitución de las jeringas que contienen por otras con un nuevo periodo de caducidad, sin que se altere la operatividad de los restantes componentes. Lejos de una situación ideal, los resultados de los estudios de estabilidad del $A I-A O D$, tanto de su solución como del propio dispositivo, permiten afirmar en concordancia con otros autores, que en una emergencia en la que sólo se disponga de un AI caducado, este debería ser usado ${ }^{4}$.

El diseño, desarrollo, producción y estudio continuado del $A I-A O D$ ha hecho posible disponer de nuevas presentaciones AI de interés militar. Las variables modificadas en el autoinyector sólo afectan al volumen descargado de cada AI, mientras se mantienen las propiedades funcionales del $A I-A O D$. La propuesta de inclusión en el próximo Petitorio de Farmacia del Ministerio de Defensa, y el inicio de su producción y distribución en el ámbito militar puede dar cumplimiento a las recomendaciones de la actual doctrina NBQ ${ }^{11}$. De los cinco nuevos AI (Figura 10), tres están disponibles contra agentes nerviosos:

- Autoinyectable de atropina ( $2 \mathrm{mg}$ en $1 \mathrm{ml}$ ) como antagonista muscarínico.

- Autoinyectable de diazepam $(10 \mathrm{mg}$ en $2 \mathrm{ml}$ ) para reducir la severidad de las convulsiones inducidas por organofosforados, si se inyecta 5-10 minutos después de que ocurran ${ }^{39}$.

- Autoinyectable Multicomponentes: atropina-pralidoxima-diazepam (2 mg, $600 \mathrm{mg}$ y $10 \mathrm{mg}$, en $3 \mathrm{ml}$ ). Combina la inhibición competitiva de la acetilcolina por la atropina, el restablecimiento de la actividad de la enzima mediante la oxima, y la acción anticonvulsivante de diazepam ${ }^{40}$.

Se dispone también de un AI con un analgésico potente:

- Autoinyectable de morfina DEF (10 mg en $1 \mathrm{ml}$ ) para alivio del dolor severo.

Así mismo, una presentación indicada en la anafilaxia grave:

- Autoinyectable de epinefrina ( $1 \mathrm{mg}$ en $1 \mathrm{ml}$ ).

No está aun disponible, pero se estudia el Autoinyectable de $D T P A$ con un $1.000 \mathrm{mg}$ de DTPA-Ca (dietilentriaminapentacetato, sal trisódico cálcica) en $4 \mathrm{ml}$ de solución inyectable, como agente de decorporación radiactiva de plutonio y otros elementos radiactivos, ante un accidente nuclear, fuga o agresión radiactiva. Se estudian también nuevos cartuchos de doble cámara ( $\mathrm{s} / 1$ - 1/l) para otros autoinyectables de interés en Defensa NBQ, y la utilización de resinas poliméricas olefínicas cíclicas ${ }^{41}$ en lugar de vidrio para la jeringa. 


\section{Estudio y caracterización del Autoinyectable de atropina-oxima DEF. Diseño de nuevos ...}

\section{CONCLUSIÓN}

Se ha presentado el Autoinyectable AJP como resultado del largo proceso de I+D que sobre autoinyectables se lleva a cabo en el CEMILFARDEF. Los resultados obtenidos en su caracterización permiten concluir que el Autoinyectable AJP cumple los requisitos exigidos por el estado actual de la ciencia, es seguro en su funcionamiento, y robusto en su resistencia al estrés estático y dinámico. Es estable y la inyección que proporciona es consistente. Se ha conseguido diseñar cinco nuevos Autoinyectables a los que, por sus características, les son aplicables los resultados obtenidos en este trabajo: Autoinyectables de Atropina, Diazepam, Morfina, Multicomponentes (atropina+pralidoxima+diazepam) y Epinefrina, todos recursos críticos necesarios en Defensa NBQ y situaciones de urgencia.

\section{BIBLIOGRAFÍA}

1. Kemp SF, Lockey RF, Simons FER. World Allergy Organization ad hoc Committee on Epinephrine in Anaphylaxis. Epinephrine: the drug of choice for anaphylaxis. A statement of the World Allergy Organization. Allergy 2008; 63:1061-1070.

2. Rebmann T, Clements BW, Bailey JA, Evans RG. Organophosphate antidote auto-injectors vs. traditional administration: a time motion study. J Emerg Med 2009; 37:139-143.

3. NATO Handbook on the medical aspects of NBC Defensive Operations. VOL III. Chemical. AMedP-6(C) VOL III. 2006

4. Frew AJ. What are the «ideal» features of an adrenaline (epinephrine) autoinjector in the treatment of anaphylaxis?. Allergy 2011; 66:15-24.

5. Nyberg A, Cassel G, Jeneskoq T, Larsson R, Lundström M, Palmer L, Persson SA. Pharmacokinetics of HI-6 and atropine in anaesthetized pigs after administration by a new autoinjector. Biopharm Drug Dispos, 1995; 16:635-51.

6. Szinicz L. History of chemical and biological warfare agents. Toxicology, 2005; 214:167-181

7. Turco SJ, King RE. Sterile Dosage Forms. Their preparation and clinical application. $3^{\text {rd }}$ Edition. Lea \& Febiger. 1987; 267-268.

8. Davis JE. Self-injectable epinephrine for allergic emergencies. J Emerg Med 2009; 37:57-62

9. Wetherell J, Price M, Mumford H, Armstrong S, Scott L. Development of next generation medical countermeasures to nerve agent poisoning. Toxicology, 2007; 233:120-127.

10. Antidote Treatment Nerve Agent, Auto-Injector. Meridian Medical Technologies. Products. Preparing to Protect. Disponible en: http://www.meridianmeds.com/products.aspx Último acceso web: 24/11/2013.

11. Original life saving chemistry. Chem Protec. Products. Disponible en:

12. http://www.chemprotect.eu/index.php?id=products Último acceso web: 24/11/2013.

13. Rathore N, Pranay P, Eu B, Ji W, Walls E. Variability in syringe components and its impact on functionality of delivery systems. PDA J Pharm Sci Technol. 2011; 65(5):468-80.

14. Sacha GA, Saffel-Clemmer W, Abram K, Akers MJ. Practical fundamentals of glass, rubber, and plastic sterile packaging systems. Pharmaceutical Development and Technology, 2010; 15(1): 6-34.

15. Normas de Correcta Fabricación. Medicamentos de uso humano y uso veterinario. Cuarta Edición. Ministerio de Sanidad. 2011.

16. Karras L, Wright L, Cox L, Kouns T, Abram, Akers MJ. Sterile prefilled syringes: Current issues in manufacturing and control. Pharmaceutical Technology 2000; 24, 10:188-196

17. Ensayo de muelles en medicina. Mecmesin. Disponible en: www.mecmesin es/ensayo-de-muelles-en-medicina. Último acceso web: 24/11/2013.

18. Challenges and Innovations with Prefilled Syringes. Soike RS. Industry Trends. 201. Supplement to BioPharm International September 2011. Dis- ponible en: http://www.highbeam.com/doc/1P3-2472611581.html Último acceso web: $24 / 11 / 2013$.

19. European Directorate for the Quality of Medicines \& HealthCare. European Pharmacopoeia 6.0, Vol. 1 y 2. 2007.

20. Avis KE, Lieberman HA, Lachman L. Pharmaceutical Dosage Forms: Parenteral medications. Marcel Dekker, inc. 1993; Vol 3. $2^{\text {nd }}$ Ed.12-14.

21. Cilurzo F, Selmin F, Minghetti P, Adami M, Bertoni E, Lauria S, Montanari L. Injectability Evaluation: An Open Issue. AAPS Pharm Sci Tech, 2011; 12,2.

22. Glass Prefillable Syringe Systems. BD Hypak SCFTM Disponible en:

23. http://www.bd.com/pharmaceuticals/products/BDHypakProductRange.asp Último acceso web: 24/11/2013.

24. Dow CorningR 365, 35\% dimethicone NF emulsion for lubrication and siliconeization of glass, metals, plastics and rubber. Disponible en:

25. http://www.dowcorning.com/applications/search/products/Details. aspx?prod=01366190\&type=PROD. Último acceso web: $24 / 11 / 2013$.

26. U.S. Pharmacopeial Convention. The United States Pharmacopeia and The National Formulary (USP24, NF19). 2000.

27. Jacobsen RC, Guess TM, Burks AW. Comparing activation and recoil forces generated by epinephrine autoinjectors and their training devices. J Allergy Clin Immunol. 2012; 129(4):1143-1145.

28. Schwirtz A, Seeger H. Are adrenaline autoinjectors fit for purpose? A pilot study of the mechanical and injection performance characteristics of a cartridge versus a syringe-based autoinjector. J Asthma and Allergy. 2010; 3:159-167.

29. Flores, G. Estadística Básica aplicada a las ciencias de la educación. Kronos. Sevilla.1995.

30. Sanchez-Ramos JJ. Autoinyector automático para la administración de medicamentos envasados en jeringa prellenadas. Boletín Oficial de la Propiedad Industrial, Marzo 1995, $\mathrm{N}^{\circ}$ publicación 2055648.

31. Orden Ministerial número 53/2004, de 18 de Marzo, por la que se establece el petitorio de farmacia del Ministerio de Defensa (B.O.D número 63, de 31 de Marzo de 2004)

32. Loch M, Zimmermann T. Atropine degradation products and trace heavy metal content in AtroPen ${ }^{\circledR}$ and ComboPen ${ }^{\circledR}$ autoinjectors. Toxicology, 2007; 1-3:229-230

33. Järvinen KM, Sicherer SH, Sampson HA, Nowak-Wegrzyn A. Use of multiple doses of epinephrine in food-induced anaphylaxis in children. J Allergy Clin Immunol 2008; 122:133-138.

34. Gaudio F, Lemery J, Johnson D. Wilderness Medical Society roundtable report: recommendations on the use of epinephrine in outdoor education and wilderness settings. Wilderness Environ Med. 2010; 21:185-187.

35. Nir Y, Paz A, Sabo E, Potasman I. Fear of injections in young adults: prevalence and associations. Am J Trop Med Hyg. 2003; 68:341-344.

36. Stecher D, Bulloch B, Sales J, Schaefer C, Keahey L. Epinephrine auto-injectors: is needle length adequate for delivery of epinephrine intramuscularly? Pediatrics. 2009; 124(1):65-70.

37. Simons FE, Roberts JR, Gu X, Simons KJ. Epinephrine absorption in children with a history of anaphylaxis. J Allergy Clin Immunol 1998; 101:33-37.

38. Simons FE, Gu X, Simons KJ. Epinephrine absorption in adults: intramuscular versus subcutaneous injection. J Allergy Clin Immunol. 2001; 108(5):871-873

39. Song TT, Nelson MR, Chang JH, Engler RJ, Chowdhury BA. Adequacy of the epinephrine auto-injector needle length in delivering epinephrine to the intramuscular tissues. Ann Allergy Asthma Immunol 2005; 94(5):539-542.

40. Simons FE, Lieberman PL, Read EJ Jr, Edwards ES. Hazards of unintentional injection of epinephrine from auto-injectors: a systematic review. Ann Allergy Asthma Immunol 2009; 102(4):282-287.

41. Simons FE, Gu X, Simons KJ. Outdated EpiPen and EpiPen Jr auto-injectors: past their prime? J Allergy Clin Immunol. 2000; 105(5):1025-1030.

42. Abbara C, Rousseau JM, Turcant A, Lallement G, Comets E, Bardot I, Clair P, Diquet B. Bioavailability of diazepam after intramuscular injection of its water-soluble prodrug alone or with atropine-pralidoxime in healthy volunteers. British Journal of Pharmacology. 2009; 157(8):1390-1397.

43. Joosen MJ, van der Schans MJ, van Helden HP. Percutaneous exposure to the nerve agent VX: Efficacy of combined atropine, obidoxime and diazepam treatment. Chem Biol Interact, 2010; 188(1): 255-263.

44. Stout D, Vilivalam V. Plastic prefilled syringes: a better fit for autoinjector systems. Pharmaceutical Technology; 2009; 33:11. 